\title{
HETEROGENEOUS FENTON CATALYTIC REACTION FOR DECOLOURIZATION OF METHYL ORANGE
}

\author{
Reeja Elsa John, Sandra Sebastian, Sandhya K Nair, Nikhi Maria Raju, David K Daniel \\ Department of Chemical Engineering, \\ Amal Jyothi College of Engineering, Kanjirappally-686518, Kerala, India
}

\begin{abstract}
Oxidation by Fenton reaction of methyl orange dye was carried out using $\mathrm{Fe}^{2+}$ impregnated on mangosteen shell as heterogeneous catalyst. The catalyst was prepared by wet impregnation method and characterized using SEM. The effectiveness of this catalyst in the decolourization of dye as well as the influence of hydrogen peroxide concentration, catalyst loading and $\mathbf{p H}$ on the decolourization efficiency was examined. In the $\mathrm{Fe}^{2+}$ loaded mangosteen catalyst, maximum decolourization efficiency of $93.3 \%$ was obtained at $\left[\mathrm{H}_{2} \mathrm{O}_{2}\right]=260 \mathrm{mM}$, catalyst loading $=0.15 \mathrm{~g} / \mathrm{l}$ and $\mathrm{pH}=7.0$ for an initial dye concentration of $30 \mathrm{ppm}$ in 180 minutes at room temperature. These findings demonstrate that the Fenton process is a promising technique for decolourization of methyl orange dye from aqueous solutions. The system is economic and environment friendly as agricultural waste material is used as a heterogeneous catalyst. The prepared catalyst can be reused for successive cycles because of their stability however there was no significant leaching of iron.
\end{abstract}

Keywords - Fenton, catalyst, decolourization, methyl orange

\section{INTRODUCTION}

Effluents from textiles, leather, cosmetics, paper, printing and plastic industries contain various kinds of synthetic dye stuffs that are harmful to the environment and have mutagenic effects (Mathur et al., 2007). Literature reports that over 15\% of the dyes are lost in wastewater without treatment during their synthesis and dyeing processes (Han et al., 2011). Since these effluents are usually strongly coloured their direct release into the water body causes damage to aquatic and human life because of their toxic and carcinogenic effects. Although a variety of techniques are presently available for treatment of such waste waters, most of them suffer from a number of disadvantages. Physical methods mostly involve transfer of the pollutant from one phase to another rather than their elimination, whereas chemical oxidation methods lead to complete mineralization of organic pollutants (Oturan et al., 2011; Nadia et al., 2016). Biological treatments are cheap but time consuming. Considering the advantages and disadvantages of the treatment processes currently available for the purification of dye laden waste water, it is a matter of great concern to develop a novel and cost effective technique for the same. Advanced oxidation processes in this regard have received great consideration recently since the target contaminants are destructed by the highly acting reactive oxygen species (Neyens et al., 2003; Liao et al., 2009; Ling et al., 2010; Nidheesh et al., 2012; George et al., 2013). The oxidation with Fenton reaction based on ferrous ion and hydrogen peroxide is an effective technique for the destruction of a variety of hazardous organic pollutants (Fenton, 1894; Daud et al., 2010; Rodriguez et al., 2010; Sun et al., 2010; Martinez et al., 2011; Gan et al., 2013; Zhu et al., 2014;). Several studies related to using Fenton reaction for the treatment of azo dyes waste waters have been conducted earlier (Gomathi et al., 2009; Nidheesh et al., 2013). Although these studies have proven this process to be effective, energy efficient and least tedious, the best outputs are available at higher concentration of $\mathrm{Fe}^{2+}$ ions and low $\mathrm{pH}$ values. In addition, large amount of iron sludge is formed due to oxidation reactions which require man power and separation techniques thereby incurring time losses and capital (Gulin, 2013). These limitations can be overcome by employing a heterogeneous Fenton catalyst combining high activity, low iron leaching and neutral $\mathrm{pH}$ environment. Therefore, in the present study mangosteen shell based catalyst for heterogeneous Fenton degradation of textile dyes was prepared, characterized and investigated for methyl orange decolourization efficiency. The study was also an attempt to further advance the use of mangosteen shells which is a major waste product of food and pharmaceutical industries (Okonogi et al., 2007; Ahmad et al., 2010). Through this work the preparation of an environmentally friendly and low cost catalyst which can be used in the treatment of dye laden waste water was realized. 


\section{MATERIALS AND METHODS}

\section{A. Reagents-}

Methyl orange $\left(\mathrm{C}_{14} \mathrm{H}_{14} \mathrm{~N}_{3} \mathrm{NaO}_{3} \mathrm{~S}\right), \mathrm{FeSO}_{4} .7 \mathrm{H}_{2} \mathrm{O}, 30 \%(\mathrm{w} / \mathrm{v})$ $\mathrm{H}_{2} \mathrm{O}_{2}$ purchased from Nice Chemicals, Kochi, India. All the chemicals used were of analytical grade and used without further purification. A known concentration of dye was prepared in distilled water and used as the stock solution for all studies.

\section{B. Preparation of iron loaded heterogeneous catalyst -}

Catalyst preparation was conducted as reported elsewhere with slight modifications (Laiju et al., 2014). Fresh mangosteen fruit was purchased from the local market and the shells were separated. The shells were washed thoroughly for removing the impurities such as dust and were dried in a hot air oven to constant weight. The dried mangosteen shells were ground and sieved to separate particles passing through BIS 200 mesh screen for further catalyst preparation. $5 \mathrm{~g}$ of mangosteen shell powder was added to $0.05 \mathrm{M}$ iron solution $\left(\mathrm{FeSO}_{4} \cdot 7 \mathrm{H}_{2} \mathrm{O}\right)$ and was mixed thoroughly with the help of a sonicator (Equitron; set power $75 \mathrm{~W}$; frequency $50 \mathrm{~Hz}$ ) for 30 minutes. After this the prepared catalyst was washed thoroughly using distilled water several times and dried in an oven at $70^{\circ} \mathrm{C}$ for $24 \mathrm{~h}$ and used for further experiments. Scanning Electron Microscopy (SEM) investigations of the mangosteen shell powder before and after loading of iron were conducted in a JEOL JSM-6390LV operated at $20 \mathrm{kV}$.

\section{Heterogeneous Fenton Experiments -}

Batch Fenton reactions were conducted in a $250 \mathrm{ml}$ iodine flask and a volume of $200 \mathrm{ml}$ was considered as the working volume for all experiments. The initial $\mathrm{pH}$ of the waste water sample of methyl orange was adjusted to 7.0. To this solution, different concentrations of catalyst and hydrogen peroxide were added. It was then kept on a rotary shaker to conduct the analysis. The samples were taken at various time intervals and the optimum values of $\mathrm{pH}$, catalyst concentration, hydrogen peroxide concentration and concentration of waste water were found out. To find the optimum value of $\mathrm{pH}$, the waste water sample was taken in 3 different iodine flasks and the $\mathrm{pH}$ was adjusted to 3.0, 7.0 and 9.0 in each. The effect of the hydrogen peroxide concentration on heterogeneous Fenton reaction was determined by taking concentrations as $0.13 \mathrm{M}, 0.26 \mathrm{M}, 0.52 \mathrm{M}$ and $1.32 \mathrm{M}$. To find out the optimum value of catalyst concentration, loadings ranging from $0.025,0.05,1.0,1.5$ and $2.0 \mathrm{~g} / \mathrm{l}$ were taken. The effect of concentration of dye was studied by taking 10, 20, 30, 50 ppm of waste water sample.

\section{Analytical methods -}

The UV-Vis spectra of the methyl orange was recorded from 200 to $800 \mathrm{~nm}$ by using UV-Visible Spectrophotometer (Shimadzu, Japan). The spectrum showed that the maximum absorbance wavelength $\left(\mathrm{k}_{\max }\right)$ of methyl orange was at 464.5 nm. Therefore, the absorbance of methyl orange in the experiment was determined at this wavelength. Before the measurement, a calibration curve was obtained using the standard methyl orange solution with a series of known concentrations. The dye decolourization efficiency was calculated as:

Decolourization efficiency $\%=\left(1-\mathrm{C}_{\mathrm{t}} / \mathrm{C}_{\mathrm{o}}\right) \times 100$

where $\mathrm{C}_{\mathrm{t}}$ and $\mathrm{C}_{\mathrm{o}}$ are the concentrations of dye at $\mathrm{k}_{\max }$ and reaction time $) 0$ and $t$ respectively.

\section{RESUlTS AND DISCUSSION}

\section{A. Effect of $\mathrm{H}_{2} \mathrm{O}_{2}$ dosage on the decolourization of methyl orange -}

$\mathrm{H}_{2} \mathrm{O}_{2}$ plays a major role as a primary source of generating hydroxyl radicals in Fenton's reaction. However, from a commercialized perspective, optimizing the concentration of hydrogen peroxide is very important (Dükkanc1 et al., 2010). The effect of $\mathrm{H}_{2} \mathrm{O}_{2}$ dosage on the degradation of methyl orange dye was examined by changing the initial concentration of $\mathrm{H}_{2} \mathrm{O}_{2}$ from $0.13 \mathrm{M}$ to $1.32 \mathrm{M}$. The results of the experiment are depicted in figure 1. From the figure, it can be observed that increasing the input of $\mathrm{H}_{2} \mathrm{O}_{2}$ from $0.13 \mathrm{M}$ to $0.26 \mathrm{M}$, the decolourization of methyl orange increased within 180 minutes of reaction. This is contributed by the elevation in hydrogen peroxide concentration which ultimately surges the production of hydroxyl radicals. But, a further escalation in $\mathrm{H}_{2} \mathrm{O}_{2}$ concentration from 0.26 to $1.32 \mathrm{M}$ showed a decrease in efficiency of the heterogeneous Fenton process. This decline in effectiveness is mainly due to the scavenging reaction occurring at a higher $\mathrm{H}_{2} \mathrm{O}_{2}$ concentration, where the $\mathrm{H}_{2} \mathrm{O}_{2}$ reacts with hydroxyl radicals to generate hydroperoxyl radical (Eq.2). The hydroperoxyl radical has as a very low oxidizing power compared to hydroxyl radicals (Fentona et al., 2009; Dükkanc1., 2010). Therefore, $0.26 \mathrm{M}$ was considered as the optimum concentration for the experiments.

$\mathrm{H}_{2} \mathrm{O}_{2}+\mathrm{OH} \cdot \rightarrow \mathrm{H}_{2} \mathrm{O}_{2}+\mathrm{HO}_{2}$ 


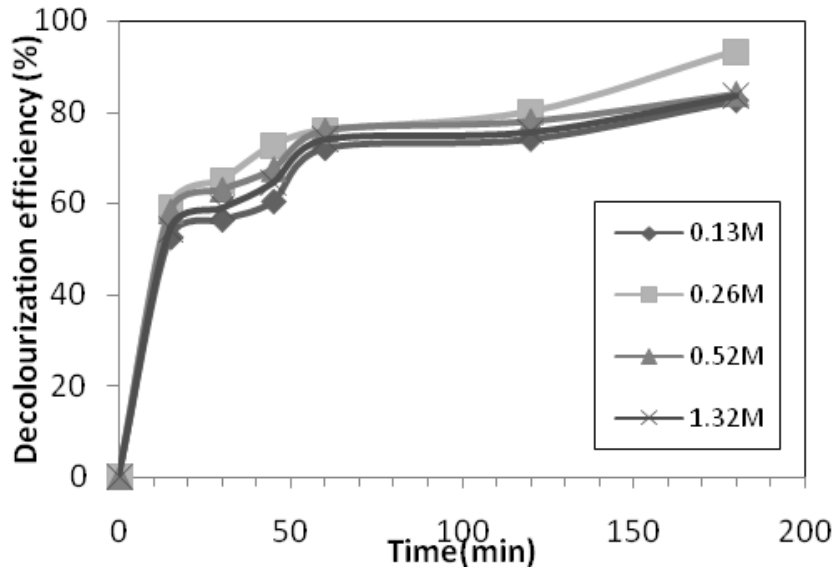

Fig. 1. Effect of hydrogen peroxide concentration on decolourization

\section{B. Effect of catalyst loading on the decolourization of methyl orange -}

To study the effect of Fe-MSP concentration on the methyl orange dye removal efficiency of the heterogeneous Fenton system, experiments were carried out with varying catalyst concentrations ranging from 0.1 to $0.2 \mathrm{~g} / \mathrm{l}$. The results of the experiment are shown in figure 2 . With a rise in catalyst concentration from 0.1 to $0.15 \mathrm{~g} / \mathrm{l}$, a notable increase was observed in the efficiency of dye decolourization. This inflation in concentration of Fe-MSP is mainly due to the increase in hydroxyl radical production. However, an additional increase in the catalyst concentration from 0.15 to $0.2 \mathrm{~g} / \mathrm{l}$ decreased the dye removal efficiency to around $70 \%$. This reduction in dye removal efficiency is mainly due to the scavenging reaction that occurs between ferrous ions and hydroxyl radicals (Brillas et al., 2009). At higher catalyst concentrations, ferrous ions react with hydroxyl radicals to form ferric ions and hydroxyl ions (Eq.3). This leads to the accumulation of ferric hydroxide precipitate. Thus, $0.15 \mathrm{~g} / \mathrm{l}$ was chosen as the optimal catalyst concentration for the experiment.

$\mathrm{Fe}^{2+}+\mathrm{OH} \rightarrow \mathrm{Fe}^{3+}+\mathrm{OH}^{-}$

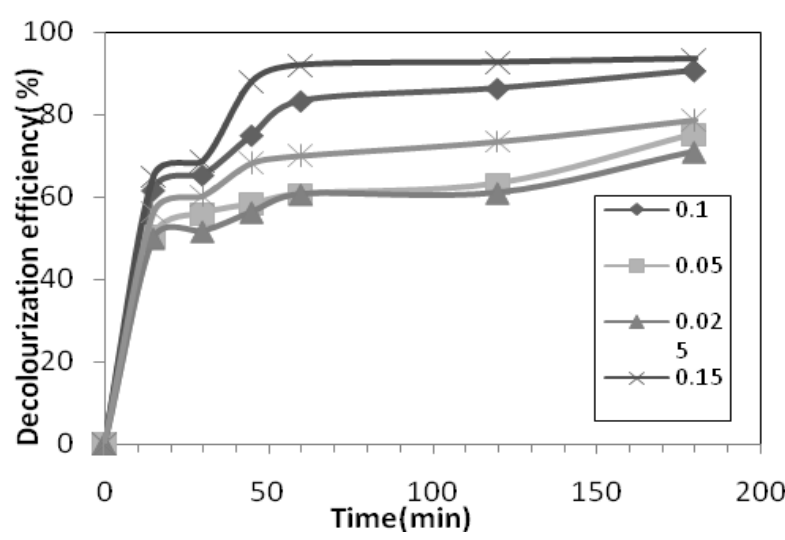

Fig. 2. Effect of catalyst concentration on dye decolourization

\section{Effect of concentration of methyl orange on the decolourization -}

The degradation of various methyl orange concentrations was studied and the results are shown in figure 3. It can be found that the decolourization efficiency of methyl orange decreased with increase in the concentrations of methyl orange. While increasing the concentration of methyl orange from 10 to 50 ppm, a significant reduction was observed in the decolourization as the efficiency dropped from $95 \%$ to $83 \%$ within $180 \mathrm{~min}$ of reaction time. This is due to a relative lower concentration of hydroxyl radicals produced compared to the concentration of methyl orange. Therefore, $10 \mathrm{ppm}$ was chosen as the desired concentration for further experiments.

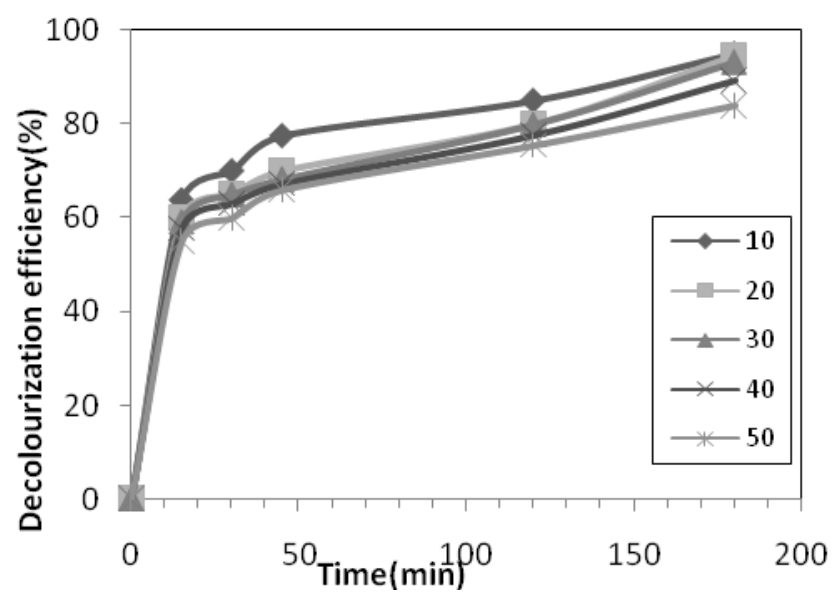

Fig. 3. Effect of concentration of methyl orange on decolourization

\section{Effect of solution pH -}

$\mathrm{pH}$ is an important parameter in any Fenton process as the lifetime of hydrogen peroxide is highly affected by the solution $\mathrm{pH}$. It is industrially accepted that the optimal 


\section{International Journal of Engineering Applied Sciences and Technology, 2020 \\ Vol. 4, Issue 9, ISSN No. 2455-2143, Pages 217-222 \\ Published Online January 2020 in IJEAST (http://www.ijeast.com)}

solution $\mathrm{pH}$ of the conventional Fenton process is around 3.0. However, Fenton reaction works even at neutral $\mathrm{pH}$, predominantly in the case of the heterogeneous Fenton process (Idel-aouad et al., 2011). Therefore, to check the effect of solution $\mathrm{pH}$ on the heterogeneous Fenton process, various experiments were administered at different $\mathrm{pH}$ levels varying from 3.0 to 9.0. The results obtained after each experiments are plotted in figure 4 . From the figure, it can be observed that the degradation efficiency of the heterogeneous Fenton process diminished with an increase in solution $\mathrm{pH}$ from 3.0 to 7.0. With an increase in solution $\mathrm{pH}$ from 7.0 to 9.0 , the removal efficiency of the system further depleted. This is mainly due to the instability of hydrogen peroxide at higher $\mathrm{pH}$ and generation of insoluble hydroxocomplexes like $\left[\mathrm{Fe}\left(\mathrm{H}_{2} \mathrm{O}\right)_{8}(\mathrm{OH})_{2}\right]^{4+}, \quad\left[\mathrm{Fe}_{2}\left(\mathrm{H}_{2} \mathrm{O}\right)_{7}(\mathrm{OH})_{3}\right]^{3+}$ and $\left[\mathrm{Fe}_{2}\left(\mathrm{H}_{2} \mathrm{O}\right)_{7}\right.$ $\left.(\mathrm{OH})_{4}\right]^{5+}$ by the iron species (Neyens et al., 2003). Moreover, at solution $\mathrm{pH} 9.0$, ferric ions tend to exist in the forms of ferric hydroxide precipitate and $\mathrm{Fe}(\mathrm{OH})^{4-}$ complex. Consequently, these complexes result in the accumulation of pollutants which will have to be removed by coagulation principles. Furthermore, at $\mathrm{pH}$ less than 3.0, considerable amounts of the ferrous and ferric ions are in $\mathrm{Fe}^{2+}$ and $\mathrm{Fe}^{3+}$ forms (Pignatello et al., 2006) making it evident that Fenton reaction is accurate at $\mathrm{pH}$ 3.0. However, the graph depicts the efficiency of neutral $\mathrm{pH}$ almost similar to $\mathrm{pH} 3.0$ for the heterogeneous Fenton reaction using Fe-MSP. Therefore, $\mathrm{pH} 7.0$ was taken as the optimal solution $\mathrm{pH}$ for this study.

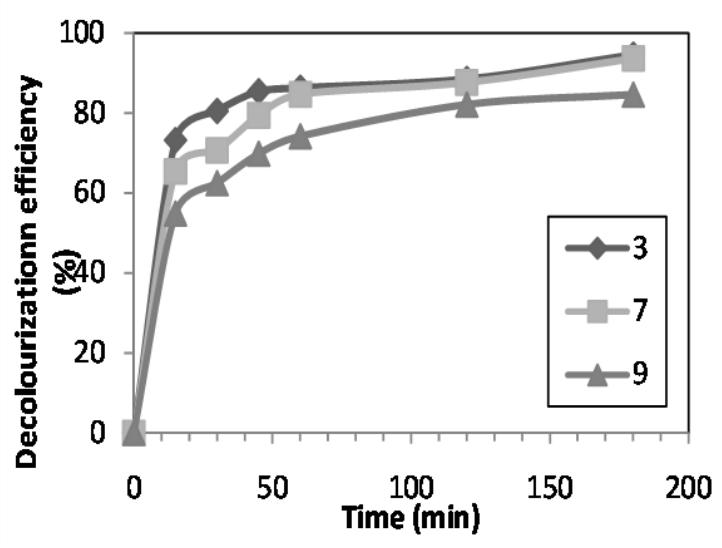

Fig. 4. Effect of $\mathrm{pH}$ on dye decolourization

\section{E. Regeneration study -}

One of the main advantages of heterogeneous Fenton reaction over homogeneous Fenton reaction is catalyst regeneration. Accordingly, to study the decolourization efficiencies of raw and recycled catalysts, a purely prepared catalyst and a residual catalyst obtained after a heterogeneous Fenton reaction were taken. A series of experiments were conducted to understand the degradation efficiencies of both catalysts in heterogeneous Fenton reaction and the result is illustrated in figure 5. It can be found out from the graph that the efficiency of raw catalyst is around $95 \%$ whereas the recycled catalyst presented a lesser value that is $70 \%$ respectively under 180 minutes. The basic factor contributing to the reduction in efficiency is the behavioral variation in the leaching pattern of the prepared catalyst (Xavier et al., 2013). Another cause is the adsorption of organic species present in the waste water to the active catalytic sites thereby poisoning the catalyst (Hassan et al., 2011) To conclude, this porous volume reduction in active sites of recycled Fe-MSP plummet the efficiency of the recycled catalyst compared to the raw catalyst.

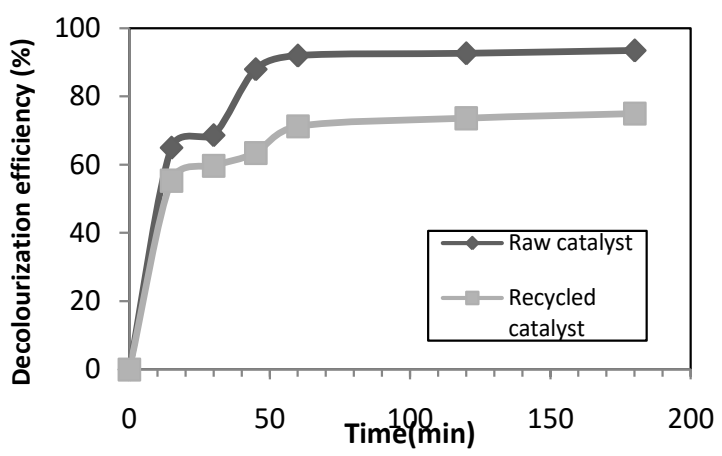

Fig. 5. Decolourization efficiency of raw and recycled catalyst

\section{CONCLUSION}

The objective of this study was to investigate the probability of decolourization of methyl orange by heterogeneous Fenton process based on environmental friendly and low-cost materials available locally. For the heterogeneous catalyst preparation, an agricultural waste material (mangosteen shell powder) was used with $0.05 \mathrm{M}$ of iron doping. Ferrous ion was loaded in these supports by incipient impregnation method using a sonicator. The results indicated that Fe-MSP based heterogeneous Fenton process can be used as a good alternative to the conventional treatment method for the treatment of dyeing wastewater. The stability of the catalyst was examined using the recycled Fe-MSP, and it was found that the efficiency of the recycled catalyst is less than that of raw Fe-MSP, due to the poisoning of active sites by the sorption of organic pollutants. The degradation of the organic pollutant in the leachate is mainly due to solid Fe ions present in Fe-MSP rather than the leached Fe ions. Under the optimal condition, the maximum dye decolourization efficiency was obtained as $93.3 \%$. The system is economic and environmental friendly as agricultural waste materials are used as a heterogeneous catalyst. 


\section{International Journal of Engineering Applied Sciences and Technology, 2020 Vol. 4, Issue 9, ISSN No. 2455-2143, Pages 217-222 \\ Published Online January 2020 in IJEAST (http://www.ijeast.com)}

\section{REFERENCE}

[1] Ahmad M.A., Alrozi R (2010). Optimization of preparation conditions for mangosteen peel-based activated carbons for the removal of Remazol Brilliant Blue R using response surface methodology. Chem. Eng. J.

(883-890).

[2] Brillas E., and Oturan M. (2009). Electro- Fenton process and related electrochemical technologies based on Fenton's reaction chemistry. Chemical Reviews , 65706631.

[3] Daud NK., Hameed BH (2010). Decolourization of Acid Red 1 by Fenton-like process using rice husk ash-based catalyst. J Hazard Mater, 938-944.

[4] Dükkancı M., Gündüz G., Yılmaz S., and Prihodko R. (2010). Heterogeneous Fenton-like degradation of Rhodamine 6G in water using CuFeZSM-5 zeolite catalyst prepared by hydrothermal synthesis. Journal of Hazardous Materials , 343-350.

[5] H. J. H. Fenton, "LXXIII.-Oxidation of tartaric acid in presence of iron," Journal of the Chemical Society, Transactions, vol. 65, pp. 899-910, 1894.

[6] Fentona R., Dotyez K., Chemizmu C.(2009). Ecol. Chem. Eng,(347-358).

[7] Gan PP, Li SFY (2013). Efficient removal of Rhodamine B using a rice hull-based silica supported iron catalyst by Fenton-like process. Chem Eng J, 351-363.

[8] George S.J., Gandhimathi R., Nidheesh P.V., Ramesh S.T. (2013). Electro fenton method oxidation of salicylic acid in aqeous solution with graphite electrodes. Environ Eng Sci, 750-756.

[9] Gomathi Devi L., Girish Kumar S., and Mohan Reddy K. (2009). Central European Journal of Chemistry , 468-477.

[10] Gulin E. (2013). Fenton-like oxidation of Reactive Black 5 using rice husk ash based catalyst. Applied catalysis B: Environmental , 353-358.

[11] Han Z., Dong Y., and Dong, S. (2011). Copper-iron bimetal modified PAN fiber complexes as novel heterogeneous fenton catalysts for degradation of organic dye under visible light irradiation. Journal of Hazardous materials , 241-248.

[12] Hassan H., and Hameed B. (2011). Fenton-like oxidation of Acid Red 1 solutions using heterogeneous catalyst based on ball clay. International Journal of Environmental Science Technology , 218-222.

[13] Idel-aouad R., Valiente M., Yaacoubi A., Tanouti B., and Lopez-Mesas M. (2011). Rapid decolourisation and mineralization of the azo dye CI Acid Red 14 by heterogeneous Fenton Reaction. Journal of Hazardous Materials , 745-750.
[14] Laiju A R., Sivasankar T., Nidheesh P V(2014). Ironloaded mangosteen as a heterogeneous Fenton catalyst for the treatment of landfill leachate. Environ Sci Pollut Res, 10900-10907.

[15] Liao Q., Sun J., Gao L (2009). Degradation of phenol by heterogeneous fenton reaction using multi-walled carbon nanotube supported $\mathrm{Fe}_{2} \mathrm{O}_{3}$ catalysts, Colloids Surf, 95100.

[16] Ling S K., Wang Y Peng.(2010). Oxidative degradation of dyes in water using $\mathrm{Co} 2+/ \mathrm{H}_{2} \mathrm{O}_{2}$ andCo2+/peroxymonosulphate, Journal of Hazardous Materials, 385-389.

[17] Martinez SS, Sanchez JV, Estrada JRM,Velasquez RF (2011). Fe(III) supported on ceria as effective catalyst for the heterogeneous photo-oxidation of basic orange 2 in aqeous solution with sunlight. Solar Energy Mater Solar Cells, 2010-2017

[18] Mathur N., and Bhatnagar P. (2007). Mutagenicity assessment of textile dyes from Sanganer (Rajasthan). Journal of Environmental Biology, 123-126.

[19] Nadia A Youssef., Seham A Shaban., Fatma A Ibrahim., Aya S Mahmoud. (2016).Degradation of methyl orange using fenton catalytic reaction. Egyptian Journal of Petroleum, 317-320.

[20] Neyens E., and Baeyens J. (2003). A review of classic Fenton's peroxidation as an advanced oxidation technique. Journal of Hazardous Materials , 33-50.

[21] Nidheesh P.V., Gandhimathi R, Ramesh ST (2013) Degradation of dyes from aqeous solution by Fenton process: a review. Environemental Science Pollution and Research, 2099-2132.

[22] Nidheesh P.V., Gandhimathi R. (2012). Trends in electrofenton process for water and waste water treatment: an overview. Desalination, 1-15.

[23] Okonogi S., Duangrat C., Anuchpreeda S., Tacchakittirungrod S., Chowwanapoonpohn S (2007). Comparison of antioxidant capacities and cytotoxicities of certain fruit peels. Food Chem, 839-846.

[24] Oturan M A., Oturan N., Edelahi MC., Podvorica FI., El Kacemi K. (2011) Oxidative degradation of herbicide diuron in aqeous medium by Fenton's reaction based advanced oxidation processes.Chemical Engineering Journal, 127-135.

[25] Pigatello J., Oliveros E., and Mackay A. (2006). Advanced Oxidation Processes for organic contaminant destruction based on the Fenton reaction and related chemistry. Critical Reviews in Environment Science and Technology , 1-84.

[26] Rodriguez A., Ovejero G., Sotelo JL., Mestanza M., Garcia J (2010). Heterogeneous Fenton catalyst supports screening for mono azo dye degradation in contaminated wastewaters. Ind Eng Chem Res, 498-505. 
[27] Sun H., Zhou G., Liu S., Ang HM., Tade MO., Wang S (2012). Nano-Fe encapsulated in microcarbon spheres: synthesis, characterization, and environemental applications. ACS Appl Mater Interfaces, 6235-6241.

[28] Xavier S., Gandhimathi R., Nidheesh P., and Ramesh S. (2013). Comparison of homogeneous and heterogeneous Fenton processes for the removal of reactive dye magenta MB from aqeous solution. Desalination and water treatment .

[29] Zhu G C., Shou J X., Qian J W., Xin . Z., and Qiu M Q. (2014). Journal of Advanced Materials Research , 10651069. 